\title{
CONTRIBUTION OF CONCRETE TO SHEAR STRENGTH OF RC BEAMS FAILING IN SHEAR
}

\author{
Guray ARSLAN, Zekeriya POLAT \\ Department of Civil Engineering, Yildiz Technical University, Istanbul, Turkey
}

Received 15 Jun. 2011; accepted 30 Sep. 2011

\begin{abstract}
Reinforced concrete (RC) beams with light transverse reinforcement are vulnerable to shear failure during seismic response. In order to prevent brittle shear failures at beam plastic hinge regions of earthquake-resistant structures, the Turkish Earthquake Code and ACI318 require the use of sufficient transverse reinforcement to resist the total expected shear demand. These codes tend to be excessively conservative and, in some cases, the contribution of the concrete to the shear strength is neglected. The aim of this study is to investigate the contribution of concrete to shear strength of RC beams failing in shear experimentally. The beams were tested under monotonically increasing reversed cyclic loading to determine the concrete contribution to shear strength. It is observed that the concrete contribution to the shear strength at ultimate state ranges from $18 \%$ to $69 \%$ of the ultimate strength.
\end{abstract}

Keywords: reinforced concrete; beam; degradation; shear failure; transverse reinforcement; cyclic loading.

Reference to this paper should be made as follows: Arslan, G.; Polat, Z. 2013. Contribution of concrete to shear strength of RC beams failing in shear, Journal of Civil Engineering and Management 19(3): 400-408.

\section{Introduction}

Extensive studies have been carried out in the past two decades to investigate the shear capacity degradation and the concrete contribution to the shear strength of reinforced concrete $(\mathrm{RC})$ members, as a function of ductility demand (Aschheim, Moehle 1992; Priestley et al. 1994; Lehman et al. 1996; ATC-32 1996; MartínPérez, Pantazopoulou 1998; Sezen, Moehle 2004), deflection capacity (Lee, Watanabe 2003), drift ratio (Elwood, Moehle 2005) and rotation capacity (Arslan 2005). The shear strength of RC frame members degrades faster than their flexural strength does under cyclic loading. Hence, the proportioning of members of new RC structures and the evaluation of members of existing structures should take into account the reduction of shear resistance (Biskinis et al. 2004). In order to prevent shear failures at beam plastic hinge regions of earthquake-resistant structures, European design codes, such as the CEB-FIP Model Code 92 (1991) and Eurocode 2 (2004), do not take into account the contribution of concrete in certain cases. Similarly, the Turkish Earthquake Code (TEC 2007) and ACI 318-08 (2008) design approach for flexural members assumes that the contribution of concrete to the shear strength of the section shall be omitted in case that shear force due to seismic loads is greater than the half of the total shear force.

Lee et al. (2009) proposed a method to predict the deformability of RC joints failing in shear after plastic hinges develop at both ends of the adjacent beams. Elmenshawi et al. (2009) conducted experiments on elements constructed with different concrete strengths (30-175 MPa) tested under load reversals in order to investigate the shear behaviour of flexural plastic hinges. Park et al. (2011) tested 10 RC columns with varying axial force ratio and shear reinforcement ratio under monotonic and reversed cyclic loading and found out that the concrete contribution to shear resistance in the plastic hinge region decreased with the increasing axial load. Chao and Loh (2009) proposed a biaxial hysteretic model to take into account the hysteretic characteristics of strength and stiffness degradation, pinching and biaxial interaction and used the test data of six RC columns to validate the model. Zhang et al. (2011) proposed a coupled hysteretic model in order to simulate the shear-flexure interactive behaviour of columns and the accumulated material damage during loading reversals, including pinching, strength deterioration, and stiffness softening, since the axial-shear-flexure interaction in columns considerably affects the strength, stiffness

Corresponding author. Guray Arslan

E-mail: aguray@yildiz.edu.tr; gurayarslan@yahoo.com 
and the hysteretic responses (Xu, Zhang 2011). Poljanšek et al. (2009) used a non-parametric empirical approach, based on empirical data on RC columns that failed in flexure, to predict the energy dissipation capacity and the deterioration of deformation capacity due to cumulative damage. Choi and Park (2010) studied the degradation in the shear capacity due to inelastic flexural deformation and developed an analytical model for predicting the degraded shear capacity and deformation capacity of slender beams by using the concept of strain-based shear strength model.

In this paper, the change in the contribution of concrete to the shear strength of RC beams failing in shear before flexural reinforcement yields was investigated experimentally. The transverse reinforcement ratio ranges from $0.22 \%$ to $0.54 \%$, while the shear span-to-depth ratio (ald) is equal to 2.5 in all beams. The beams were tested under monotonically increasing reversed cyclic loading. The curves of shear forcedeflection and shear force-contribution of transverse reinforcement to shear force are plotted based on experimental results.

\section{Shear strength of beams}

The following procedure outlines the guidelines recommended by MacGregor (1973) to determine the shear strength of RC members. The governing equation given by ACI 318-08 (2008) states that the shear strength must exceed the shear demand as shown in Eqn (1):

$$
\phi V_{n} \geq V_{u} .
$$

Most of the shear design equations (ACI 318-08 2008; TS500 2000) provide a simple superposition of transverse reinforcement and concrete strength. The ACI 318-08 (2008) design shear strength is independent of whether flexural yield has occurred prior to shear failure. For members, design shear strength is calculated as follows:

$$
V_{\mathrm{n}}=V_{\mathrm{c}}+V_{\mathrm{s}}=\frac{\sqrt{f_{\mathrm{c}}}}{6} b_{\mathrm{w}} d+\frac{A_{\mathrm{w}} f_{\mathrm{y}} d}{S}
$$

where $V_{\mathrm{c}}$ is the contribution of concrete to shear strength; $V_{\mathrm{s}}$ is the contribution of transverse reinforcement to shear strength based on yield; $f_{\mathrm{c}}$ is the compressive strength of concrete in $\mathrm{MPa} ; b_{\mathrm{w}}$ is the beam width; $d$ is the effective depth; $A_{\mathrm{v}}$ is the area of shear reinforcement within a distance $s$ and $f_{\mathrm{y}}$ is the transverse reinforcement yield strength. In the ACI 318-08 (2008), the contribution of vertical transverse reinforcement is derived from basic equilibrium considerations on a 45-degree truss model with constant transverse reinforcement spacing and an effective depth (ASCE-ACI Committee 445 on Shear and Torsion 1998).

In the TS500 (2000) equation, the contribution of concrete to shear strength is mainly dependent on the compressive strength of concrete. Eqn (3) represents the shear strength of slender beams:

$$
V_{\mathrm{n}}=V_{\mathrm{c}}+V_{\mathrm{s}}=\left(0.2275 \sqrt{f_{\mathrm{c}}}+\rho_{\mathrm{w}} f_{\mathrm{yw}}\right) b_{\mathrm{w}} d,
$$

where $\rho_{\mathrm{w}}$ is the transverse reinforcement ratio $\left(\rho_{\mathrm{w}}=\right.$ $\left.A_{\mathrm{v}} /\left(b_{\mathrm{w}} s\right)\right)$ and $f_{\mathrm{c}}$ is in MPa.

In seismic design, according to the TEC (2007), shear force, $V_{\mathrm{e}}$, is to be taken into account for beam transverse reinforcement and shall be calculated using Eqn (4) such that the most unfavourable result is obtained by considering the cases of earthquake acting from left to right or from right to left separately:

$$
V_{\mathrm{e}}=V_{\mathrm{dy}} \mp\left(M_{\mathrm{pi}}+M_{\mathrm{pj}}\right) / l_{\mathrm{n}},
$$

where $M_{\mathrm{pi}}$ and $M_{\mathrm{pj}}$ are the positive or negative ultimate moment capacities considering strain hardening of steel; $V_{\mathrm{dy}}$ is the simple beam-shear developed at the column face due to vertical loads; and $l_{\mathrm{n}}$ the is clear span of beam. Unless a more rigorous analysis is performed, ultimate moment capacities at the beam ends may be taken as $M_{\mathrm{pi}} \cong 1.4 M_{\mathrm{ri}}$ and $M_{\mathrm{pj}} \cong 1.4 M_{\mathrm{rj}}$, where $M_{\mathrm{ri}}$ is the positive or negative ultimate moment resistance calculated on left end $i$ of a beam and $M_{\mathrm{rj}}$ is the negative or positive ultimate moment resistance calculated on right end $j$. The ACI 318-08 (2008) requires beams to be designed to resist the shear corresponding to the development of ultimate moment capacity, considering strain hardening of steel, $M_{\mathrm{pr}}$, using conventional ACI procedures with transverse reinforcement yield stress taken equal to 1.25 times the nominal yield stress, at the both ends of the member. In ACI 318-08 (2008) and TEC (2007), within the plastic-hinge region, when the shear due to seismic effects is equal to or greater than the gravity shear, the transverse reinforcement is to be designed to provide $V_{\mathrm{s}}$ assuming $V_{\mathrm{c}}=0$.

Figure 1 illustrates the existing models for predicting shear capacity degraded by inelastic deformation. The change of concrete shear strength, $V_{\mathrm{c}}$, and shear capacity, $V_{\mathrm{n}}$, with displacement ductility is given according to the models of Priestley et al. (1994) and Sezen and Moehle (2004). The relationship between shear capacity and drift ratio, defined as a function of transverse reinforcement ratio, plastic shear capacity and axial force, is given by the model of Elwood and Moehle (2005). According to the model of Lee and Watanabe (2003), the shear contribution of concrete and the effective compressive strength of concrete $v f_{\mathrm{c}}$ as a function of deflection are depicted. The model of Arslan (2005) assumes that the contribution of transverse reinforcement is equal to the ultimate strength of beam. As can be seen, these models predict a reduction in the contribution of concrete to shear strength for increasing displacement ductility, drift ratio, deflection and rotation, with a small residual strength at large ductility levels. 


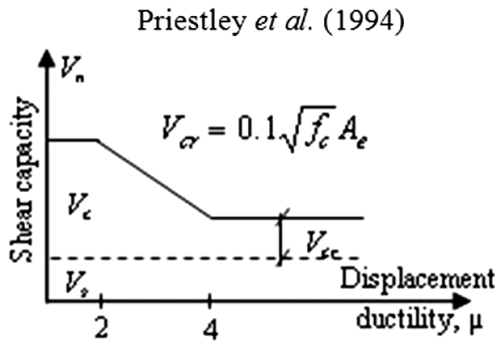

$V_{c-}$ shear capacity of concrete; $V_{S}$ - shear capacity of transverse; reinforcement provided by 30 degree truss model;

$V_{c r-\text { residual shear capacity of concrete }}$

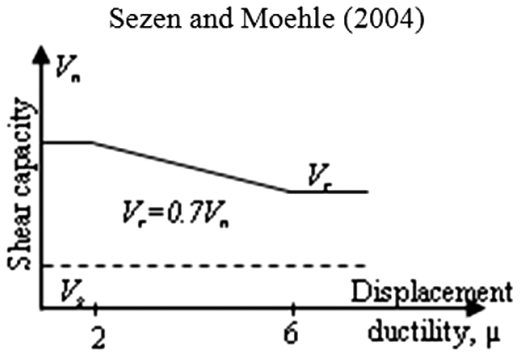

$V_{c}$ - shear capacity of concrete based on the diagonal tension failure mechanism; $V_{s}$ - shear capacity of transverse reinforcement provided by 45 degree truss model

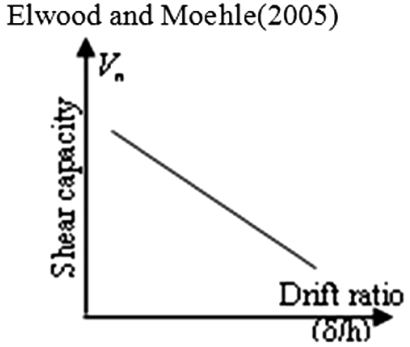

$\delta / h$ - drift ratio at shear failure defined as a function of transverse reinforcement ratio, plastic shear capacity and axial force

Lee and Watanabe (2003)

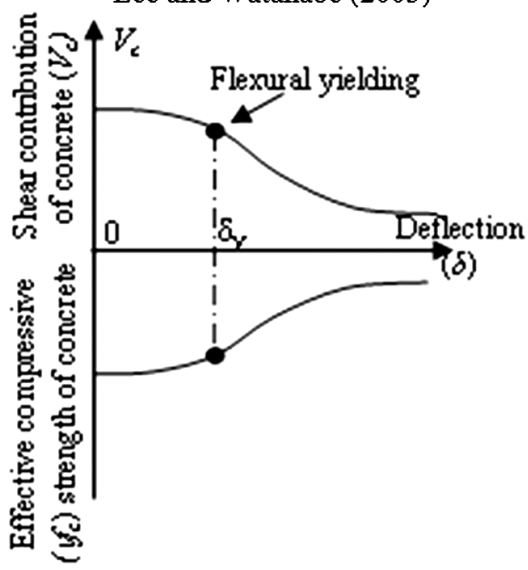

Arslan (2005)

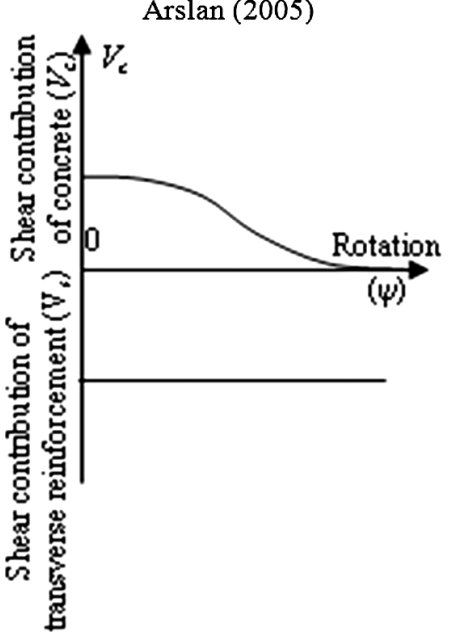

Fig. 1. Existing shear degradation models for predicting shear capacity

\section{Experimental programme}

\subsection{Test variables}

Figure 2 shows the arrangement of the reinforcement and the cross-sectional dimensions of RC beams (Polat et al. 2007; Arslan et al. 2008). All beams are $150 \mathrm{~mm}$ wide $\left(b_{\mathrm{w}}\right), 230 \mathrm{~mm}$ effective deep $(d)$ and supported with a span length of $1150 \mathrm{~mm}$. The shear span-to-depth ratios $(a / d)$ of all beams were kept constant at a value of 2.5 to ensure shear failure rather than bending failure. Four different transverse reinforcement space configurations were used, where the transverse reinforcement ratios $\left(\rho_{\mathrm{w}}\right)$ range from $0.22 \%$ to $0.54 \%$. The beam designation includes a combination of letters and numbers: $\mathrm{H}$ to indicate the series; 16 and 22 to designate the diameter of tensile and compression reinforcement; $\mathrm{S}$ to indicate the transverse reinforcement spacing; 125, 155, 250 and $310 \mathrm{~mm}$ to designate the spacing of transverse reinforcements. For example, a beam of series $\mathrm{H}$ having a transverse reinforcement spacing of $125 \mathrm{~mm}$ with the diameter of tensile and compression reinforcement equal to $22 \mathrm{~mm}$ is designated as $\mathrm{H} 22 \mathrm{~S} 125$.

The properties of the beams are shown in Table 1. While computing $\rho_{\mathrm{w}(\mathrm{TS} 500)}$ and $\rho_{\mathrm{w}(\mathrm{ACI} 318)}$, the required shear strength was taken as the shear strength
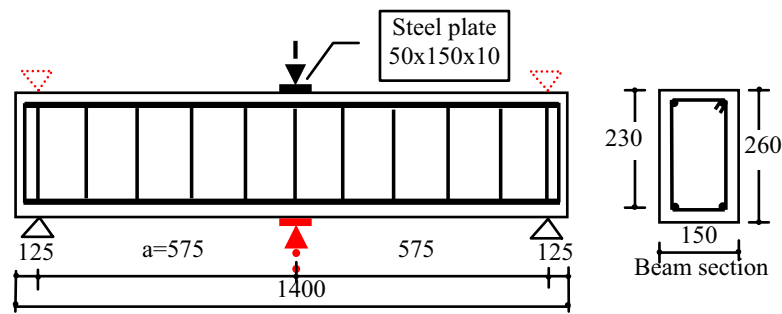

Fig. 2. Geometry of $\mathrm{H} 22 \mathrm{~S} 125$ beam and reinforcement arrangement (unit: $\mathrm{mm}$ ) 
Table 1. Properties of beams

\begin{tabular}{lccccc}
\hline Beam & $\rho_{\mathrm{w}}(\%)$ & $\frac{\rho_{\mathrm{w}}}{\rho_{\mathrm{w}(\mathrm{TS} 500)}}$ & $\frac{\rho_{\mathrm{w}}}{\min \rho_{\mathrm{w}(\mathrm{TS} 50)}}$ & $\frac{\rho_{\mathrm{w}}}{\rho_{\mathrm{w}(\mathrm{AC} 318)}}$ & $\frac{\rho_{\mathrm{w}}}{\min \rho_{\mathrm{w}(\mathrm{AC} 318)}}$ \\
\hline H16S125 & 0.54 & 2.77 & 4.58 & 2.26 & 6.43 \\
H16S155 & 0.43 & 2.21 & 3.64 & 1.80 & 5.12 \\
H16S250 & 0.27 & 1.39 & 2.29 & 1.13 & 3.21 \\
H22S125 & 0.54 & 0.93 & 4.58 & 0.87 & 6.43 \\
H22S155 & 0.43 & 0.74 & 3.64 & 0.69 & 5.12 \\
H22S250 & 0.27 & 0.47 & 2.29 & 0.43 & 3.21 \\
H22S310 & 0.22 & 0.38 & 1.86 & 0.35 & 2.62 \\
\hline
\end{tabular}

corresponding to the yielding of longitudinal reinforcement. The ratios of transverse reinforcements in the beams were determined in such a way that they are larger than the minimum ratios defined by TS500 (2000) and ACI 318-08 (2008), and smaller than the ratio computed from the shear strength corresponding to the yielding of longitudinal reinforcement.

\subsection{Materials}

Concrete composition is the same for all the beams. A concrete mix consisting of Portland cement (PC 42.5) and a maximum aggregate size of $22 \mathrm{~mm}$ in diameter was used. A superplasticiser with retarder which meets ASTM C494/C494M-12 (2012) requirements for Type A admixture was used in the mix to achieve good workability. The concrete mix proportions for $1 \mathrm{~m}^{3}$ of concrete are given in Table 2.

The average tensile and compressive strengths of concrete were found to be 1.55 and $25.0 \mathrm{MPa}$, respectively. The diameters of deformed bars used for reinforcing beams are 16 and $22 \mathrm{~mm}$. The bars have an average yield strength of $420 \mathrm{MPa}$ and a tensile strength of $550 \mathrm{MPa}$. The transverse reinforcements have a diameter of $8 \mathrm{~mm}$ and an average yield strength of $393 \mathrm{MPa}$ and tensile strength of $526 \mathrm{MPa}$.

\subsection{Testing and instrumentation}

The test beams were placed within a testing frame shown schematically in Figure 3 and subjected to reversed cyclic loading. Hinged connections were ensured between the specimens and the testing frame. Both ends of the beams were free to rotate and move horizontally under load. The test beams were subjected to single-point loads as shown in Figure 3.

Table 2. Mix proportions of concrete

\begin{tabular}{lc}
\hline Material & Quantity $\left(\mathrm{kg} / \mathrm{m}^{3}\right)$ \\
\hline Water/Cement CEMI 42.5R & $194 / 310$ \\
$0-2 \mathrm{~mm}$ natural sand & 451 \\
$0-5 \mathrm{~mm}$ crushed sand & 221 \\
$5-12 \mathrm{~mm}$ crushed stone & 522 \\
12-22 mm crushed stone & 655 \\
Superplasticiser & 1.86 \\
\hline
\end{tabular}

The test set-up includes the use of a hydraulic jack that applies load gradually at the mid-span of beam specimens until failure. The beams were loaded monotonically up to the approximately $11.0-13.5 \%$ of their estimated ultimate loads at first steps, and then continuously loaded in a series of load-controlled cycles. Three full cycles were performed at each load level. Finally, the increments were reduced by about $50 \%$ of initial load increments, and the imposed loads were increased up to the ultimate loads.

The strains in two transverse reinforcements in the shear span (labelled as S1 and S2 in Fig. 6) were measured. In order to monitor the development of strain in the transverse reinforcements with progressive loading, an electrical strain gauge was installed to the reinforcement directly. The net deflections of the beams were recorded by linear variable displacement transducers (LVDTs). A computer-aided data acquisition system automatically monitored load, deflections and strains at pre-selected time intervals. The tests also provided information on the overall behaviour of beams, including development of cracks, crack patterns and failure modes.

\section{Results and discussion}

\subsection{General cracking and failure behaviour of test beams}

Figure 4 shows crack patterns of RC beams at failure. The cracks were outlined with blue, red and black felt tip markers and labelled at each loading step. During early stages of loading, fine vertical flexural cracks appeared around the mid-span of all the beams, as expected. With the increase in load, new flexural cracks were formed away from the mid-span area. With further increase in reversed cyclic load, those flexural cracks started to propagate diagonally towards the loading point, and other new diagonal cracks began to form at locations farther away from the mid-span along the beam (Fig. 4). No slipping failure of longitudinal reinforcements and transverse reinforcements was observed in all the beams. This can be regarded as satisfying the requirements of TEC (2007) and is enough to prevent slipping failure.

A diagonal crack is defined as a major inclined crack, extending from the level of the flexural 


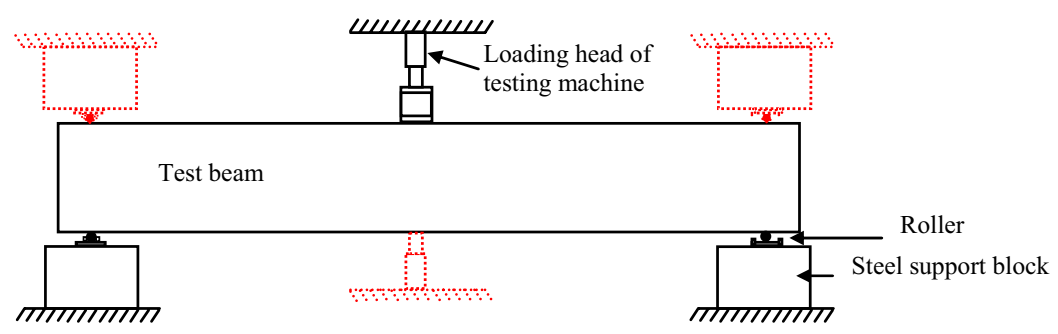

Fig. 3. Details of testing arrangement
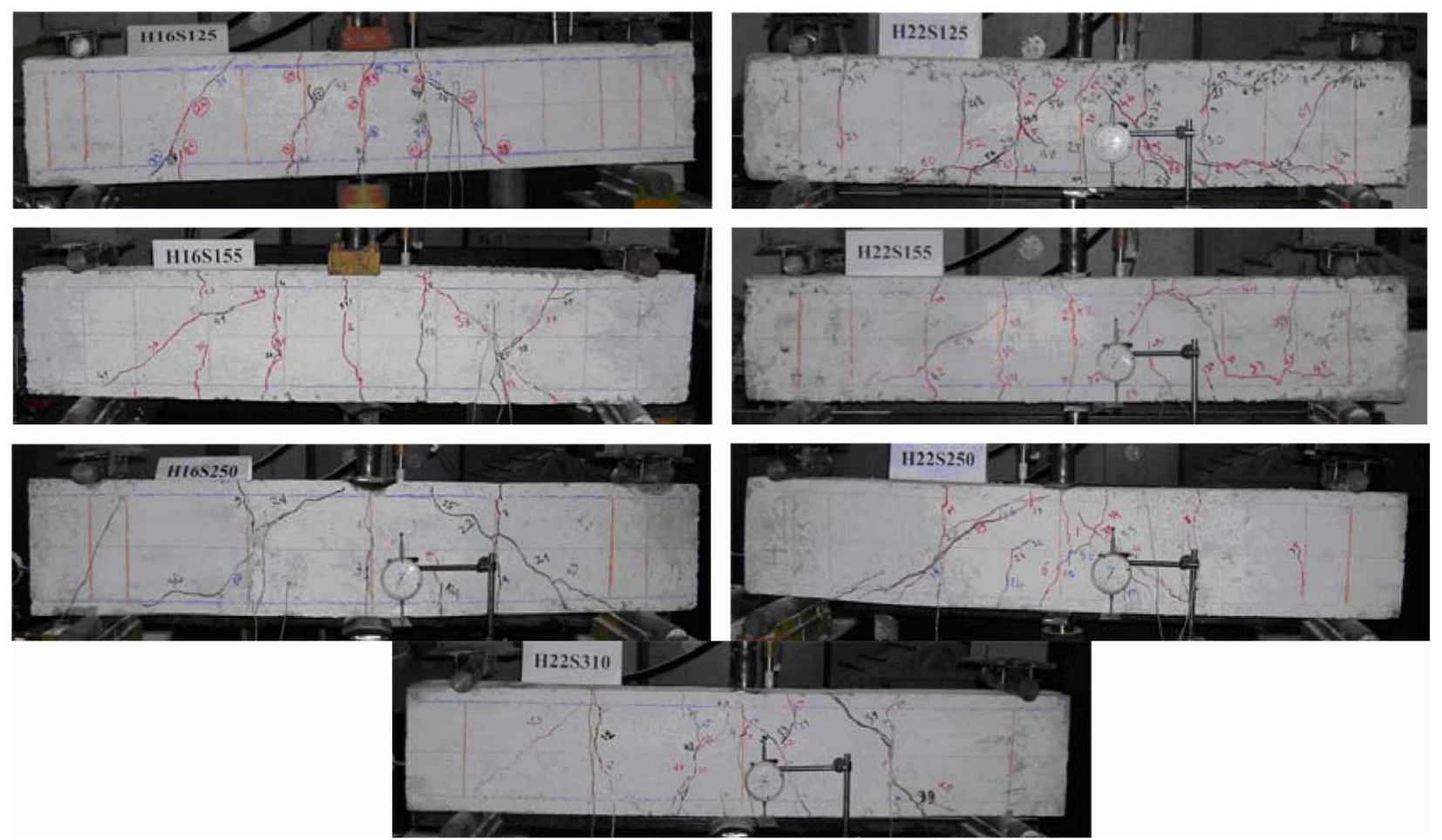

Fig. 4. Crack patterns of RC beams at failure

reinforcement towards the application point of the load, and the load at the growth of this first inclined crack is termed as the diagonal tension-cracking load $\left(P_{\mathrm{cr}}\right)$. The load at the growth of first flexural crack is termed as the flexural crack load $\left(P_{\mathrm{fl}}\right)$. Table 3 shows the variation of diagonal cracking load $\left(P_{\mathrm{cr}}\right)$, flexural

Table 3. Flexural/diagonal cracking and ultimate loads

\begin{tabular}{|c|c|c|c|c|c|}
\hline & $P_{\mathrm{fl}}^{\mathrm{a}}(\mathrm{kN})$ & $P_{\mathrm{cr}}^{\mathrm{b}}(\mathrm{kN})$ & $P_{\mathrm{u}}(\mathrm{kN})$ & $\frac{P_{\mathrm{fl}}}{P_{\mathrm{u}}}$ & $\frac{P_{\mathrm{cr}}}{P_{\mathrm{u}}}$ \\
\hline Beam & (1) & (2) & (3) & $(1) /(3)$ & $(2) /(3)$ \\
\hline H16S125 & 20 & 60 & 115 & 0.17 & 0.52 \\
\hline H16S155 & 20 & 60 & 120 & 0.17 & 0.50 \\
\hline $\mathrm{H} 16 \mathrm{~S} 250$ & 30 & 70 & 118 & 0.25 & 0.59 \\
\hline $\mathrm{H} 22 \mathrm{~S} 125$ & 40 & 80 & 170 & 0.24 & 0.47 \\
\hline $\mathrm{H} 22 \mathrm{~S} 155$ & 40 & 60 & 174 & 0.23 & 0.34 \\
\hline $\mathrm{H} 22 \mathrm{~S} 250$ & 20 & 80 & 148 & 0.14 & 0.54 \\
\hline $\mathrm{H} 22 \mathrm{~S} 310$ & 30 & 75 & 135 & 0.22 & 0.56 \\
\hline
\end{tabular}

${ }^{\text {a }}$ Flexural cracks extended up to mid-height of the beam.

${ }^{b}$ Diagonal cracks extended up to mid-height of the beam. crack load $\left(P_{\mathrm{f} 1}\right)$ and ultimate load $\left(P_{\mathrm{u}}\right)$ of beams having varying tensile/compression reinforcement ratios and transverse reinforcement spaces.

\subsection{Comparison of shear force-deflection curves of beams}

Figure 5 shows a comparison of the shear forcedeflection curves obtained from the experiments. For the beams having similar longitudinal reinforcement ratios (H16 and $\mathrm{H} 22$ series), the shear strength and the deflection capacity of the beam having less transverse reinforcement are smaller. For all the beams, mid-span deflections at each level of load, which was applied in reverse directions three times, were compared. It was observed that there is no significant difference in the mid-span deflections at different cycles, and the difference in the deflections in reverse directions at the same cycle does not exceed $10 \%$. This may be a result of the fact that the homogeneity of concrete is provided along the depth of beam. 


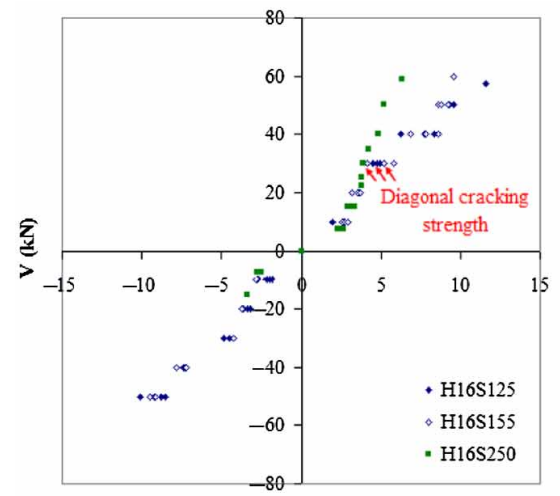

Deflection (mm)

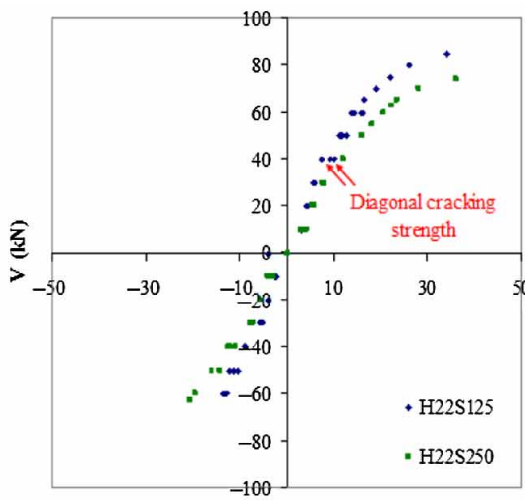

Deflection (mm)

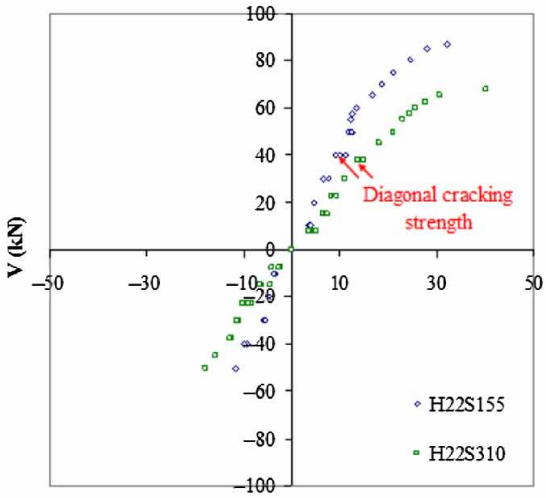

Deflection (mm)

Fig. 5. Shear force-deflection curves of beams

\subsection{Contributions of transverse reinforcement and concrete to shear force}

The contributions of transverse reinforcement and concrete to shear force were calculated as follows:

- For each value of strain, stress in the transverse reinforcement was computed from stress-strain curve by iteration;

- The contribution of transverse reinforcement to the shear force was computed by multiplying the ratio of transverse reinforcement with the stress in the transverse reinforcement and crosssectional area of the beam $\left(b_{\mathrm{w}} d\right)$;
- For each value of the applied load, the contribution of transverse reinforcement $\left(V_{\mathrm{s}}\right)$ to the shear force $(V)$ was computed by averaging results from measurements obtained at two transverse reinforcements (S1 and S2);

- The contribution of concrete $\left(V_{\mathrm{c}}\right)$ to the shear force was computed by subtracting the average contribution of transverse reinforcement to the shear force from the shear force due to the applied load.

In the beams H16S155, H22S125 and H16S125, the strains measured in the transverse reinforcement (S2) farther away from the applied load are greater
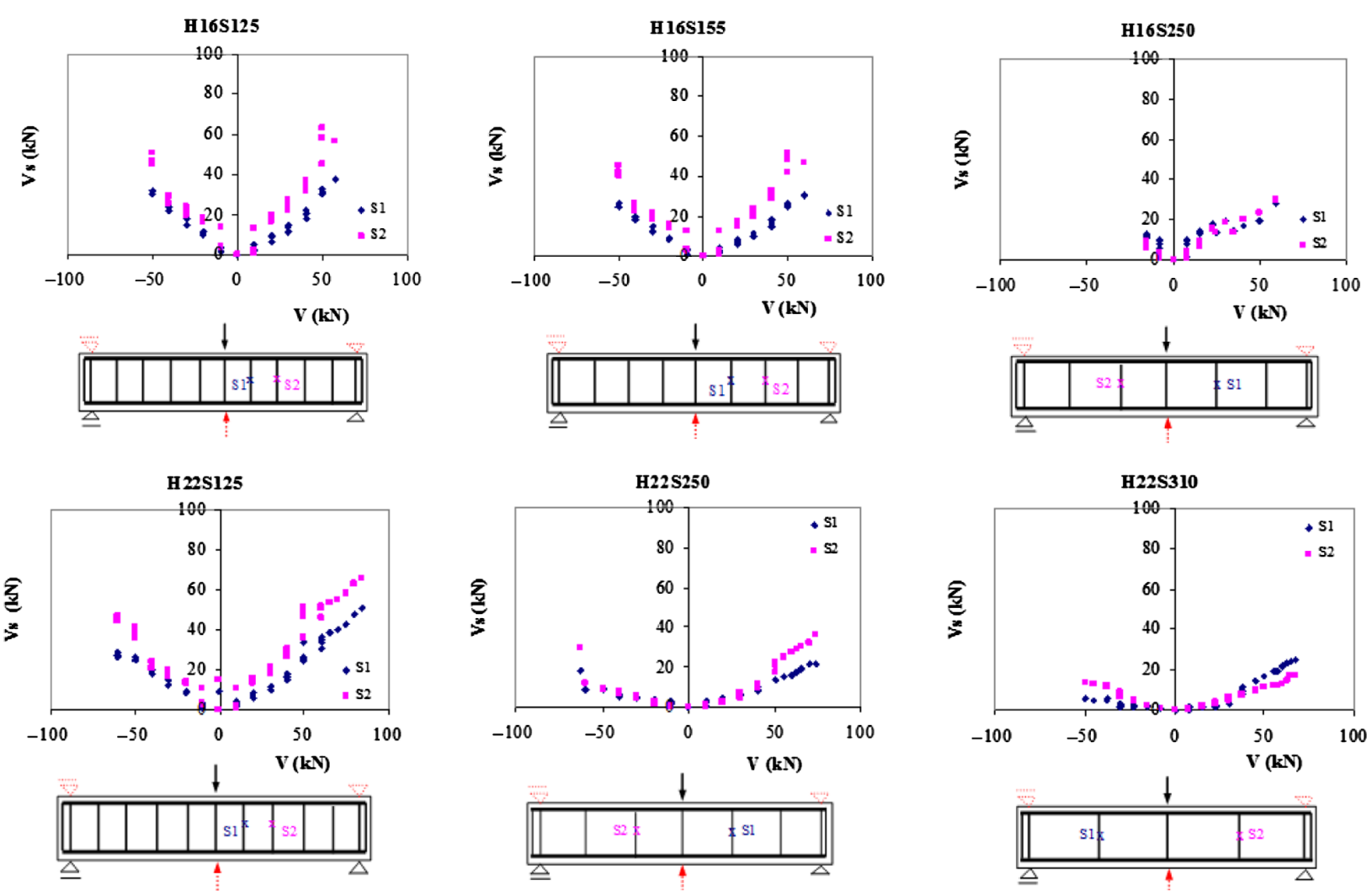

Fig. 6. The contribution of transverse reinforcement to shear force 

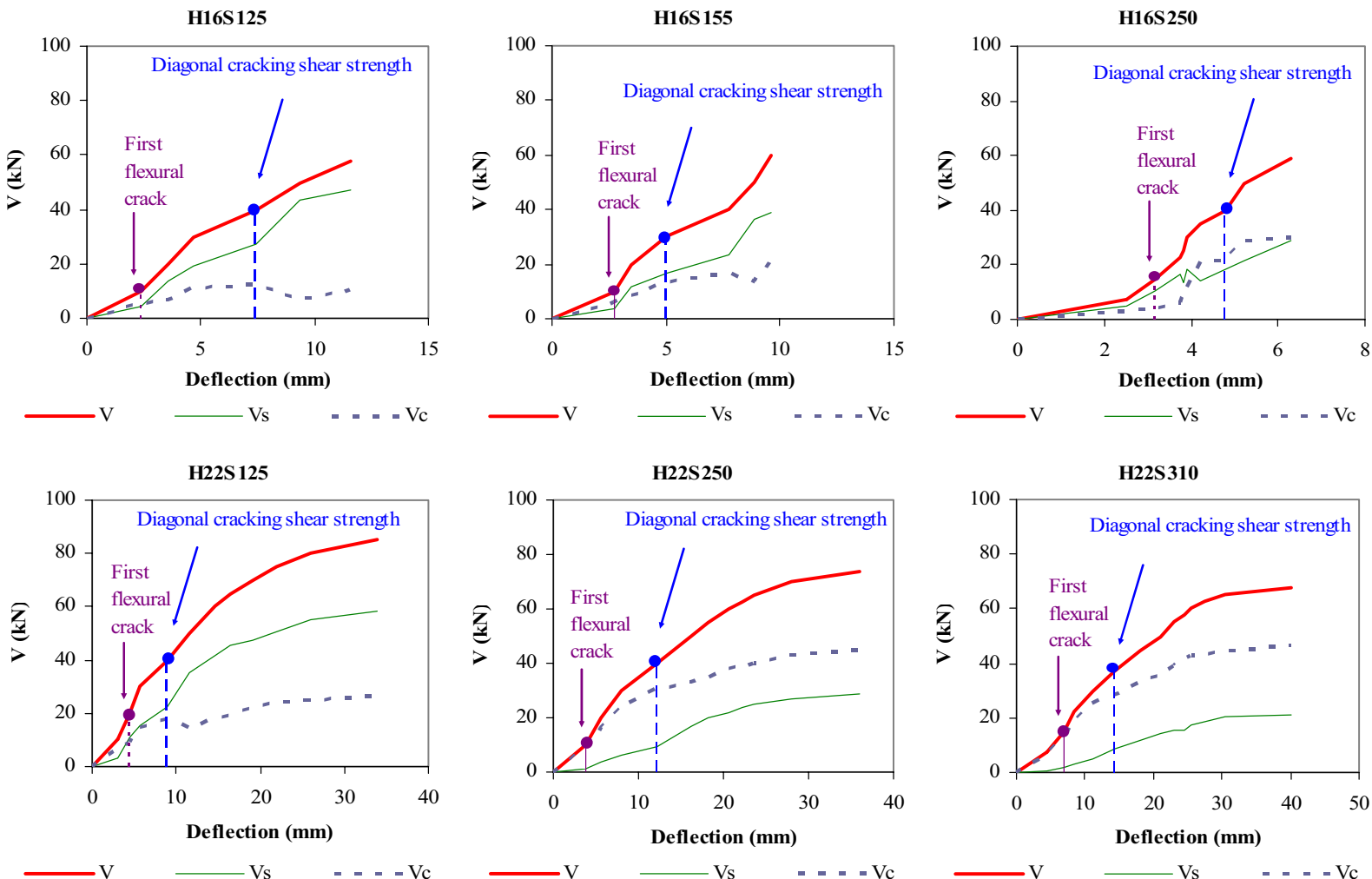

Fig. 7. Contribution of concrete and transverse reinforcement to shear force

than the ones (S1) close to the applied load. However, the strains in $\mathrm{S} 2$ are less than the ones in $\mathrm{S} 1$ in the beam $\mathrm{H} 22 \mathrm{~S} 310$ (Fig. 6). The measurements on the beam $\mathrm{H} 22 \mathrm{~S} 155$ were not taken into account since the strain gauges installed in the transverse reinforcements of $\mathrm{H} 22 \mathrm{~S} 155$ failed beyond $40 \mathrm{kN}$.

It was observed that yielding strain in the transverse reinforcement, thus yielding stress, was not reached in the beams H16S125, H16S250, $\mathrm{H} 22 \mathrm{~S} 125$ and $\mathrm{H} 22 \mathrm{~S} 310$ at the load levels close to the ultimate strength in spite of the increase of the strain in the transverse reinforcement. In the beams $\mathrm{H} 22 \mathrm{~S} 250$ and H16S155, it was observed that the strain S2 reached the yielding strain at the load level corresponding to the ultimate strength. The degradation of strength and stiffness in RC beams under increasing reversed cyclic loading is primarily due to the fact that crack openings are unable to close.

In the beams H22S125 and H22S250, while the contributions of transverse reinforcement and concrete to the shear force were similar until the first shear crack extending up to mid-height of the beam was observed, the contribution of transverse reinforcement to the shear force increased with the increasing load after the shear cracks extending up to mid-height of the beam were observed. It can be concluded that the transverse reinforcement becomes more effective with the increasing load after the shear cracks extend up to mid-height of the beam (Fig. 7).

Relative increases of the strains in the transverse reinforcements of beams H16S125, H16S155, $\mathrm{H} 16 \mathrm{~S} 250, \mathrm{H} 22 \mathrm{~S} 125, \mathrm{H} 22 \mathrm{~S} 250$ and $\mathrm{H} 22 \mathrm{~S} 310$ were

Table 4. Shear strength of beams

\begin{tabular}{|c|c|c|c|c|c|c|c|c|c|}
\hline Beam & $V_{\text {cr(TS500) }}(\mathrm{kN})$ & $V_{\mathrm{cr}(\mathrm{ACI} 318)}(\mathrm{kN})$ & $V_{\mathrm{c}}^{\mathrm{a}}(\mathrm{kN})$ & $\frac{V_{\mathrm{c}}}{V_{\mathrm{cr}(\mathrm{TS} 500)}}$ & $\frac{V_{\mathrm{c}}}{V_{\mathrm{c}(\mathrm{AC} 1318)}}$ & $V_{\mathrm{s}}^{\mathrm{b}}(\mathrm{kN})$ & $V_{\mathrm{u}}(\mathrm{kN})$ & $\frac{V_{\mathrm{c}}}{V_{\mathrm{cr}}}$ & $\frac{V_{\mathrm{c}}}{V_{\mathrm{u}}}$ \\
\hline $\mathrm{H} 16 \mathrm{~S} 125$ & 34.85 & 28.64 & 10.35 & 0.30 & 0.36 & 47.27 & 57.62 & 0.35 & 0.18 \\
\hline H16S155 & 34.85 & 28.64 & 21.39 & 0.61 & 0.75 & 38.64 & 60.03 & 0.71 & 0.36 \\
\hline $\mathrm{H} 16 \mathrm{~S} 250$ & 34.85 & 28.64 & 30.02 & 0.86 & 1.05 & 28.98 & 59.00 & 0.86 & 0.51 \\
\hline $\mathrm{H} 22 \mathrm{~S} 125$ & 34.85 & 28.64 & 26.57 & 0.76 & 0.93 & 58.31 & 84.87 & 0.66 & 0.31 \\
\hline H22S155 & 34.85 & 28.64 & - & - & - & - & 86.94 & - & - \\
\hline $\mathrm{H} 22 \mathrm{~S} 250$ & 34.85 & 28.64 & 45.20 & 1.30 & 1.58 & 28.98 & 74.18 & 1.13 & 0.61 \\
\hline $\mathrm{H} 22 \mathrm{~S} 310$ & 34.85 & 28.64 & 46.58 & 1.34 & 1.63 & 21.05 & 67.62 & 1.24 & 0.69 \\
\hline
\end{tabular}

${ }^{\mathrm{a}}$ Contribution of concrete to shear strength.

${ }^{\mathrm{b}}$ Contribution of transverse reinforcement to shear strength. 
observed under increasing loads after shear cracks extending up to mid-height of beams were observed.

Table 4 presents cracking shear force according to TS500 (2000) and ACI 318-08 (2008), calculated as $V_{\mathrm{cr}(\mathrm{TS} 500)}=0.2275 \sqrt{f_{\mathrm{c}}} b_{\mathrm{w}} d$ and $V_{\mathrm{c}(\mathrm{ACI} 18)}=\sqrt{f_{\mathrm{c}}} b_{\mathrm{w}} d / 6$, respectively, experimental cracking shear force $\left(V_{\mathrm{cr}}\right)$ and the contribution of concrete to the shear strength at ultimate state $\left(V_{\mathrm{u}}\right)$. It is observed that there exists a contribution of concrete to the shear strength at ultimate state even under reversed loading. It can be stated that the contribution of concrete to the shear strength at ultimate state ranges from $18 \%$ to $69 \%$ of the ultimate strength.

For H16 series of beams, the contributions of concrete to the shear strength of H16S125, H16S155 and $\mathrm{H} 16 \mathrm{~S} 250$ are $0.30,0.61$ and 0.86 times the cracking shear strength defined by TS500 (2000). The contributions of concrete to the shear strength of H16S125, H16S155 and H16S250 are 0.36, 0.75 and 1.05 times the cracking shear strength defined by ACI 318-08 (2008). It can be stated that the contribution of concrete to the shear strength at ultimate state ranges from $35 \%$ to $86 \%$ of the experimental diagonal cracking shear strength (Table 4).

For H22 series of beams, the contributions of concrete to the shear strength of H22S125, H22S 250 and $\mathrm{H} 22 \mathrm{~S} 310$ are $0.76,1.30$ and 1.34 times the cracking shear strength defined by TS500 (2000). The contributions of concrete to the shear strength of $\mathrm{H} 22 \mathrm{~S} 125, \mathrm{H} 22 \mathrm{~S} 250$ and $\mathrm{H} 22 \mathrm{~S} 310$ are $0.93,1.58$ and 1.63 times the cracking shear strength defined by ACI 318-08 (2008). It can be stated that the contribution of concrete to the shear strength at ultimate state ranges from $66 \%$ to $124 \%$ of the experimental diagonal cracking shear strength (Table 4).

\section{Conclusions}

The change in the contribution of concrete to the shear strength of RC beams under increasing reversed cyclic loading was investigated experimentally. The following conclusions can be drawn.

According to the Turkish Earthquake Code (2007) and ACI 318-08 (2008), in the case of excessive shear force the contribution of concrete to the shear strength is neglected. This approach tends to be excessively conservative. A gradual reduction assessment may be much more reasonable in the strength and stiffness of $\mathrm{RC}$ beams for structures resisting the seismic actions:

- The degradation of shear strength and stiffness in $\mathrm{RC}$ beams under increasing reversed cyclic loading is primarily due to the fact that crack opening are unable to close in the beams H16S155 and H22S250 because of the yielding of transverse reinforcement across the beams;
- The average contributions of transverse reinforcements and concrete to the shear force were similar until the first shear crack extending up to mid-height of the beam was observed. The contribution of transverse reinforcement to the shear force increased with the increasing load after the shear cracks extending up to mid-height of the beam were observed. It can be concluded that the transverse reinforcement becomes more effective with the increasing load after the shear cracks extend up to mid-height of the beam;

- The experiments show that there exists a significant amount of contribution of concrete to the shear strength (18-69\%). However, further experiments should be conducted with a wider range of transverse reinforcement ratio, shear span-to-depth ratio, concrete strength and various loading schemes in order to obtain more reliable assessments.

\section{Acknowledgements}

The financial support from the Research Fund of Yildiz Technical University, Turkey (Project No. 24-05-01-02), for the research reported herein is gratefully acknowledged. The authors would also like to thank the Set Italcementi Group North Marmara district office for material supply.

\section{References}

ACI 318-08. 2008. Building code requirements for structural concrete and commentary. Farmington Hills, MI: American Concrete Institute. 473 p.

Arslan, G. 2005. Shear strength of reinforced concrete frame members under cyclic loads. PhD thesis. Turkey: Yildiz Technical University.

Arslan, G.; Polat, Z.; Köksal, H. O. 2008. Investigation on shear degradation of $\mathrm{RC}$ beams under cycled loads, in The 8th International Congress on Advances in Civil Engineering ( $A C E$ ), 15-17 September, 2008, Famagusta, N. Cyprus.

ASCE-ACI Committee 445 on Shear and Torsion. 1998. Recent approaches to shear design of structural concrete, Journal of Structural Engineering ASCE 124(12): 1375-1417. http://dx.doi.org/10.1061/(ASCE)0733-9445(1998) 124:12(1375)

Aschheim, M.; Moehle, J. P. 1992. Shear strength and deformability of $R C$ bridge columns subjected to inelastic cyclic displacements. Berkeley, CA: Earthquake Engineering Research Center, University of California at Berkeley. $99 \mathrm{p}$.

ASTM C494/C494M-12. 2012. ASTM C494/C494M-12 standard specification for chemical admixtures for concrete. USA: American Society for Testing and Materials (ASTM). $10 \mathrm{p}$.

ATC-32. 1996. ATC-32 improved seismic design criteria for California bridges: provisional recommendations. Redwood City, CA: Applied Technology Council. 205 p.

Biskinis, D. E.; Roupakias, G. K.; Fardis, M. N. 2004. Degradation of shear strength of reinforced concrete members with inelastic cyclic displacements, $A C I$ Structural Journal 101(6): 773-783. 
CEB-FIP Model Code 92. 1991. CEB-FIP model code 1990. Bulletin d'Information No. 203/204/205, Committee Euro-International du Beton, Lausanne, Switzerland. $437 \mathrm{p}$.

Chao, S.-H.; Loh, C.-H. 2009. A biaxial hysteretic model for a structural system incorporating strength deterioration and pinching phenomena, International Journal of Non-Linear Mechanics 44(7): 745-756. http://dx.doi.org/10.1016/j.ijnonlinmec.2009.04.005

Choi, K.-K.; Park, H.-G. 2010. Evaluation of inelastic deformation capacity of beams subjected to cyclic loading, ACI Structural Journal 107(5): 507-515.

Elmenshawi, A.; Brown, T.; Loov, R. 2009. Behaviour of flexural plastic hinges under high seismic shear with consideration of concrete strength, Canadian Journal of Civil Engineering 36(11): 1711-1721. http://dx.doi.org/10.1139/L09-099

Elwood, K. J.; Moehle, J. P. 2005. Axial capacity model for shear-damaged columns, ACI Structural Journal 102(4): 578-587.

European Committee for Standardization. 2004. Eurocode 2: design of concrete structures. Part 1-1: general rules and rules for buildings. Brussels. $225 \mathrm{p}$.

Lee, J.-Y.; Kim, J.-Y.; Oh, G.-J. 2009. Strength deterioration of reinforced concrete beam-column joints subjected to cyclic loading, Engineering Structures 31(9): 20702085.

http://dx.doi.org/10.1016/j.engstruct.2009.03.009

Lee, J.-Y.; Watanabe, F. 2003. Shear deterioration of reinforced concrete beams subjected to reversed cyclic loading, ACI Structural Journal 100(4): 480-489.

Lehman, D. E.; Lynn, A. C.; Aschheim, M. A.; Moehle, J. P. 1996. Evaluation methods for reinforced concrete columns and connections, in Proc. of the 11th World Conference on Earthquake Engineering, 22-28 June, 1996, Acapulco, Mexico. Elsevier Science Ltd., Paper No. 673.

MacGregor, J. G. 1973. The shear strength of reinforced concrete members, Journal of Structural Division 99(6): 1091-1187.

Martín-Pérez, B.; Pantazopoulou, S. J. 1998. Mechanics of concrete participation in cyclic shear resistance of $\mathrm{RC}$, Journal of Structural Engineering ASCE 124(6): 633-641.
http://dx.doi.org/10.1061/(ASCE)0733-9445(1998)124: 6(633)

Park, J.; Cha, S.; Kang, J.; Mansour, M. M.; Lee, J. 2011. Axial strain of reinforced concrete columns, Advanced Materials Research 163-167: 1858-1861.

Polat, Z.; Köksal, H. O.; Arslan, G. 2007. Shear strength of reinforced concrete frame members under cyclic loads. Scientific Research Project of Yildiz Technical University (24-05-01-02), Turkey.

Poljanšek, K.; Peruš, I.; Fajfar, P. 2009. Hysteretic energy dissipation capacity and the cyclic to monotonic drift ratio for rectangular RC columns in flexure, Earthquake Engineering \& Structural Dynamics 38(7): 907-928. http://dx.doi.org/10.1002/eqe.875

Priestley, M. J. N.; Verma, R.; Xiao, Y. 1994. Seismic shear strength of reinforced concrete columns, Journal of Structural Engineering ASCE 120(8): 2310-2329. http://dx.doi.org/10.1061/(ASCE)0733-9445(1994) 120:8(2310)

Sezen, H.; Moehle, J. P. 2004. Shear strength model for lightly reinforced concrete columns, Journal of Structural Engineering ASCE 130(11): 1692-1703. http://dx.doi.org/10.1061/(ASCE)0733-9445(2004) 130:11(1692)

TEC. 2007. Turkish earthquake code. Specification for structures to be built in disaster areas. Ministry of Public Works and Settlement Government of Republic of Turkey, Ankara, Turkey. $161 \mathrm{p}$.

TS500. 2000. TS500 Requirements for design and construction of reinforced concrete structures. Ankara, Turkey: Turkish Standards Institute. 67 p. (in Turkish).

Xu, S.- Y.; Zhang, J. 2011. Hysteretic shear-flexure interaction model of reinforced concrete columns for seismic response assessment of bridges, Earthquake Engineering \& Structural Dynamics 40(3): 315-337. http://dx.doi.org/10.1002/eqe.1030

Zhang, J.; Xu, S.- Y.; Tang, Y. 2011. Inelastic displacement demand of bridge columns considering shear-flexure interaction, Earthquake Engineering \& Structural Dynamics 40(7): 731-748. http://dx.doi.org/10.1002/eqe.1056

Guray ARSLAN. Associate Professor at the Department of Civil Engineering, Yildiz Technical University. He received his Ph.D. from the University of Yildiz Technical, Istanbul, Turkey. His main research interest is the behaviour of reinforced concrete members under monotonic and cyclic actions.

Zekeriya POLAT. Professor, retired from Yildiz Technical University in 2008. His research interests include performance-based earthquake engineering and the development of structural design standards. 